\title{
Health priorities and the social determinants of health
}

\author{
Michael Marmot ${ }^{1}$ and Jessica Allen ${ }^{2}$
}

Here's a paradox. Ministers of health are the government ministers most concerned with health. Yet their prime responsibility is for health services, not with key determinants of health that lie outside the health care system. The paradox extends to the World Health Organization (WHO). WHO is governed by ministers of health yet its remit is to improve health in the populations it serves. Such improvement requires universal health coverage, of course, but much more besides: improvement in the conditions in which people are born, grow, live, work and age - the social determinants of health (1).

Without such action, the great inequalities in health between and within countries of the WHO Eastern Mediterranean Region (EMR) cannot be addressed. Improvements in health across the Region have been uneven, dramatically so. Within EMR, male life expectancy varies among countries from 51 to 79 years; female life expectancy from 55 to 82 years (2). These inequalities in health are largely unnecessary and have their origins in unfair social arrangements, and are not the product of physiological or genetic differences. These 27 and 28 year gaps in life expectancy require action across society, not only in the health care sector, and reducing these inequities is a matter of social justice as well as good economics.

Within countries of EMR, inequalities are more difficult to document, particularly for adult mortality, as such data are less readily available; in many countries conflict and population movement and displacement means collecting such data is challenging. A major task therefore for the EMR is to document social inequalities in adult mortality, and monitor trends. We do have data, however, on infant and childhood mortality and the evidence is clear: a social gradient in mortality exists - the lower the household income the higher the mortality. In our European Review of Social Determinants and the Health Divide (3), and elsewhere (4), we have highlighted this issue of the gradient. However, inequalities in health between social groups are not confined to poor health for the poor, and reasonable health for the non-poor. The fact that these inequalities run from top to bottom of the social hierarchy implies clearly that remedial action must be across the whole of society, and action is required in all government arenas. Nonetheless, ministers of health are the stakeholders best placed to lead this cross society, across government action.

To tackle the issue of high risk for excluded groups and the social gradient in health, we are developing the principle of proportionate universalism. Experience from the Nordic countries shows how important universalist policies are to improving social conditions and health across the whole of society (5). Yet, high risk groups require special focus. Hence the principle of proportionate universalism: universalist policies with effort proportionate to need.

A second principle of action can be described as "the causes of the causes". Evidence shows clearly that the conditions of daily life, and access to health care, are important causes of ill-health.
But why are they distributed unevenly in society? We need to address the causes of the causes - the social determinants of life style, access to clean water, shelter, and good nutrition. Inequities in power, money and resources must be part of the focus.

Such action requires knowledge and evidence both of the nature and magnitude of health inequalities, and the effects of actions. But it also requires political commitment from the top and the involvement of individuals and communities who are affected.

The WHO Regional Office for the Eastern Mediterranean (EMRO) has adopted five priorities for the Region: health systems strengthening; maternal, reproductive and child health and nutrition; communicable diseases; noncommunicable diseases; and emergency preparedness and response. To make progress, each of these areas requires action on the social determinants of health, and health equity to be made the centre of attention.

We plan to work with EMRO on these issues over the coming months to learn from Member States both about the nature of the problem and good examples of action, and to share learning and experiences from countries outside the Region.

EMR, in particular, as well as dealing with social and gender inequalities is also facing the serious issue of violent conflict. At the heart of action on social determinants ofhealth is a commitment to creating fairer, more just, and socially inclusive societies. It is a reasonable 
presumption that such actions, morally informed, will be important steps towards resolving conflicts. The causes of good health and of security are likely to have much in common.
Emerging from our European Review was the exhortation: do something, do more, do better. This appeal is equally relevant to EMR countries. Whatever the state of development of a country, whatever the challenges thrown up by civil unrest and conflict, there is always the possibility of doing something, doing more, and doing it better.

\section{References}

1. Commission on the Social Determinants of Health. Closing the gap in a generation: health equity through action on the social determinants of health. Final report of the Commission on Social Determinants of Health. Geneva: World Health Organization; 2008.

2. World Health Statistics 2014. Geneva: World Health Organization; 2014.

3. Marmot M, Allen J, Bell R, Bloomer E, Goldblatt P; Consortium for the European Review of Social Determinants of Health and the Health Divide. WHO European review of social de- terminants of health and the health divide. Lancet. 2012 Sep 15;380(9846):1011-29. PMID:22964159

4. Marmot M. Fair society, healthy lives: the Marmot review; strategic review of health inequalities in England post-2010. London: The Marmot Review; 2010.

5. Lundberg O, Aberg Yngwe M, Kolegard Stjarne M, Bjork L, Fritzell J. The Nordic experience: welfare states and public health (NEWS). Stockholm: Centre for Health Equity Studies (CHESS); 2008:12 (Health Equity Studies No 12). 